\title{
A importância do tratamento em hospital-dia para a criança com subnutrição primária
}

Maria PaUla de AlbUQUERQUe, PAULA ANDREA Martins, Renata CRISTina Pires e ANA LYdia SAWATA

\section{Introdução}

1

SUBNUTRIÇÃo é resultado de uma complexa associação de fatores sociais, econômicos e biológicos, fortemente relacionada às condições de moradia de uma população e frequentemente associada às infecções (Black et al., 2008). Mais prevalente em áreas superpovoadas de países em desenvolvimento, afeta de forma especial alguns grupos como crianças abaixo de cinco anos, gestantes, portadores de doenças crônicas, pacientes hospitalizados e idosos. A subnutrição está relacionada a mais de um terço de todas as mortes de crianças menores de cinco anos, sendo uma das principais preocupações em saúde no mundo (WHS, 2009).

As principais repercussões da subnutrição infantil em curto prazo são, portanto maior suscetibilidade a processos infecciosos e o aumento da mortalidade infantil (Farhat; Faria, 1998). Na vigência de déficit nutricional, as infecções respiratórias e intestinais estão aumentadas e a resposta metabólica ante a infecção está prejudicada, levando ao ciclo vicioso infecção-subnutrição, sendo a subnutrição causa e efeito das infecções (Shimeles; Lulseged, 1994; Zaman, 1997). O risco de morte por diarreia em crianças (< 5 anos) é 4,6 vezes maior quando ela apresenta baixa estatura ou nanismo grave (estatura para idade: $\mathrm{E} / \mathrm{I}<-3$ escores z) e 9,5 vezes maior quando a criança apresenta magreza grave (peso para idade: $\mathrm{P} / \mathrm{I}<-3$ escore $\mathrm{z}$ ) (Black et al., 2008). Com relação à pneumonia, o risco de morte é 3,2 vezes maior e 6,4 vezes maior em crianças com baixa estatura e magreza graves respectivamente (ibidem).

Após décadas de avanços no sistema de saúde, no acesso a alimentos e medicamentos, observa-se uma redução da mortalidade infantil e da prevalência da subnutrição em nosso país. O novo perfil nutricional mostra queda significativa das formas graves de subnutrição como marasmo e kawashiorkor, mas a baixa estatura ou nanismo de causa nutricional continua a ser um problema de grandes proporções, principalmente na população de baixo poder aquisitivo (Pesquisa de Orçamento..., 2010). A prevalência de baixa estatura (E/I <- 2 escores z) em menores de cinco anos de idade é semelhante em meninos e me- 
ninas: $6,3 \%$ e $5,7 \%$, sendo mais evidente no primeiro ano de vida $(8,4 \%$ e $9,4 \%$, respectivamente). A região Norte apresenta a maior prevalência com $8,5 \%$ das crianças afetadas. Nota-se, ainda, forte tendência de redução da prevalência de baixa estatura com o aumento da renda (de $8,2 \%$ no estrato de menor renda para $3,1 \%$ no estrato de maior renda), denotando a forte determinação que a renda familiar ainda exerce sobre o risco de subnutrição infantil no Brasil (ibidem). Nesse sentido, cabe afirmar que a baixa estatura é um marcador de pobreza. Nos países em desenvolvimento, a participação genética na etiologia da baixa estatura tem pouca relevância quando comparada às fortes evidências da contribuição ambiental para o quadro (Frongillo et al., 1997; Martorell et al., 1998).

Idealizados para o combate à subnutrição infantil primária e criados na década de 1960, os Centros de Recuperação Nutricional (CRN) colaboraram com expressiva redução da mortalidade infantil em vários países da América Latina, como Chile e Guatemala (Sawaya, 1997) e ainda hoje são importantes recursos no enfrentamento da subnutrição em países como a Índia (Taneja et al., 2012). Esse modelo de tratamento ainda hoje é recomendado pela Organização Mundial de Saúde (OMS) para o manejo da subnutrição grave, uma vez que permite o oferecimento da melhor terapia disponível, redução do risco de morte, diminuição do tempo de permanência hospitalar e facilitação da reabilitação e recuperação nutricional completa (WHO, 1999).

Este artigo apresenta os resultados do tratamento de crianças com subnutrição primária atendidas em regime de hospital-dia no Centro de Recuperação e Educação Nutricional (CREN) em São Paulo.

\section{Métodos}

\section{Local do estudo}

O CREN oferece três tipos de atendimento: diretamente junto à comunidade (através de visitas domiciliares e supervisão de instituições), ambulatorial e hospital-dia. As crianças com subnutrição moderada/grave (0-60 meses) são atendidas em hospital-dia e provêm de famílias com maior risco social. O encaminhamento para ingresso no CREN ocorre a partir de censos com avaliações antropométricas realizadas nas favelas e nas creches, especialmente aquelas próximas às comunidades carentes, além de encaminhamento de outros serviços de saúde e de assistência (Figura 1)

À criança em hospital-dia é oferecido tratamento clínico, que consiste no diagnóstico e na terapêutica precoces dos processos infecciosos e/ou mórbidos e das carências nutricionais específicas. Os casos que necessitam de atendimento diferenciado são encaminhados para o hospital terciário de referência.

Após a internação em hospital-dia, ocorre complementação diagnóstica, através dos seguintes exames laboratoriais: protoparasitológico (três amostras), urina tipo I e urocultura, hemograma completo, perfil lipídico, cálcio, fósforo, fosfatase alcalina, ferro sérico, ferritina e transferrina, repetidos a cada seis meses. 


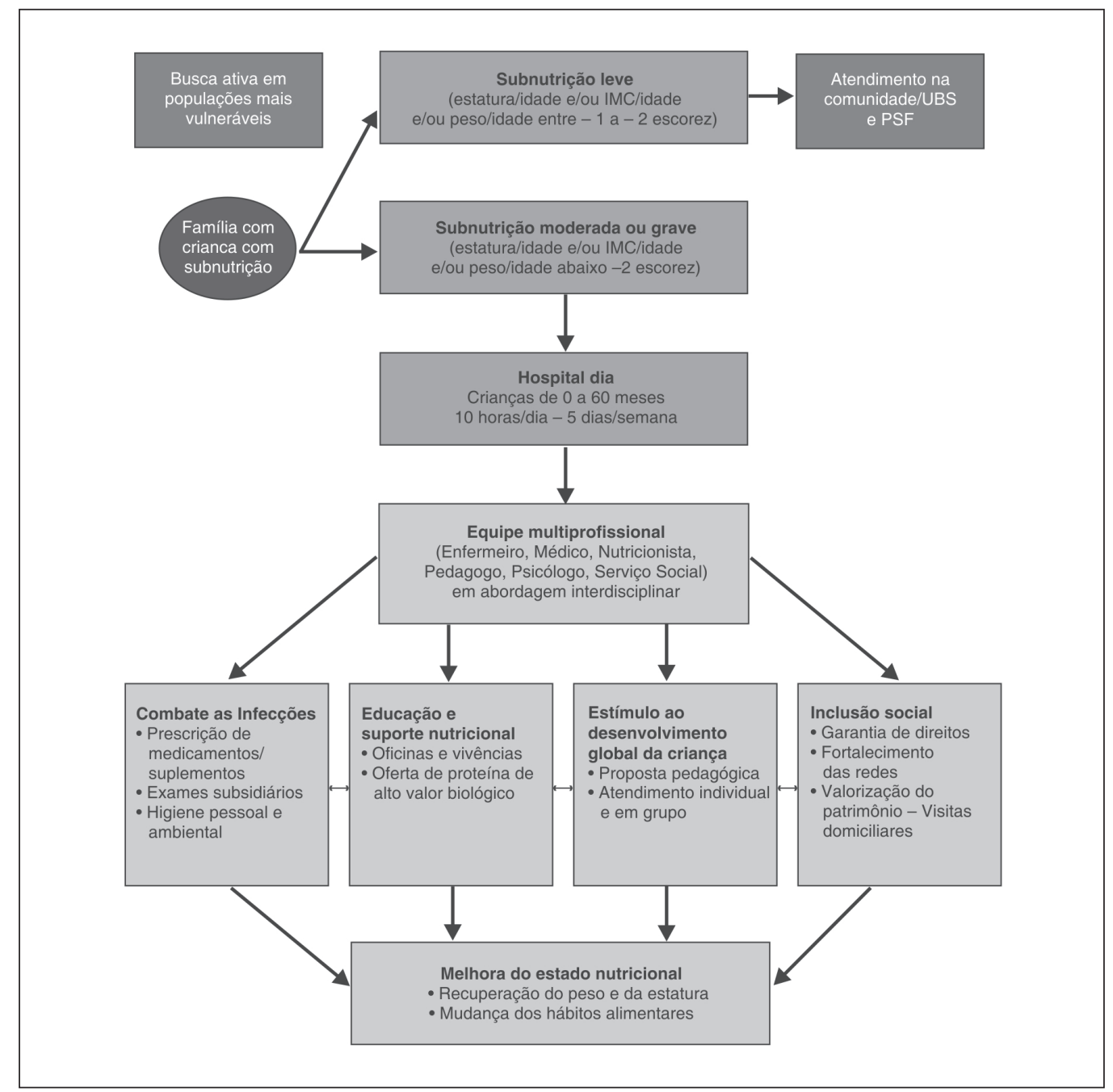

Figura 1 - Fluxo de encaminhamento/atendimento do hospital-dia.

Quando há um moderado comprometimento estatural, investiga-se também a idade óssea. Outros exames (RX de tórax, ultrassom abdominal, fundo de olho, hormônios e sorologias, entre outros) são solicitados conforme a necessidade do caso clínico.

O centro oferece ainda atividades psicopedagógicas para as crianças em hospital-dia.

A alta do hospital-dia ocorre por ocasião da recuperação da subnutrição, ou seja, de todos os parâmetros acima de -1,64 escores z (percentil 10) (Frisancho, 1993), ou por critério de idade, para as crianças maiores de 60 meses, devido à necessidade de inserção no ensino fundamental. Nesse momento a criança é encaminhada para outra instituição (creche ou pré-escola). Sempre que possível, é feito um período de adaptação da criança ao seu novo ambiente. Após a alta, a criança permanece em acompanhamento ambulatorial. 


\section{Abordagem dos processos infecciosos}

Nas crianças do presente estudo, a anamnese era realizada diariamente logo que a criança chegava ao centro por profissional de enfermagem, quando eram coletadas informações sobre a presença de febre; sintomas respiratórios como tosse, coriza ou dispneia; sintomas gastrointestinais como vômitos, diarreia e eliminação de parasitas. No decorrer do dia esse realizava o controle de sinais vitais (temperatura, frequência cardíaca e respiratória), a observação da ingestão alimentar, da frequência ou consistência anormal das fezes, tosse, coriza ou vômitos independentemente do relato dos pais ou responsáveis na admissão.

O exame físico era realizado por único pediatra e o atendimento registrado em prontuário. Quando confirmada doença infecciosa ou parasitária, o medicamento era dispensado na própria unidade pela enfermagem que orientava o responsável pela criança para a administração em domić́lio quando necessário.

O diagnóstico das Infecções de Vias Áreas Superiores (IVAS) era realizado da seguinte forma: sinusites, na presença de tosse persistente (predominantemente noturna), secreção nasal por mais de dez dias e cefaleia frontal, associado ou não a febre e dor em região de seios da face; resfriado comum, definido como infecção respiratória alta com congestão nasal, rinorreia e inflamação da garganta, de etiologia viral; faringites, definidas como inflamação das estruturas faríngeas com aparecimento de eritema, edema, exsudato faríngeo, úlcera e vesículas, na maioria das vezes de etiologia viral, geralmente associada a coriza e tosse. $\mathrm{Na}$ diferenciação da etiologia em bacteriana ou viral, dados clínicos como intensidade e tempo de existência da febre, presença ou não de exsudato e adenopatia cervical reacional com infarto ganglionar foram utilizados como critério clínico para a prescrição do antibiótico; e as otites foram identificadas pela presença de otalgia, com secreção em orelha média, otorreia, hiperemia de membrana timpânica com ou sem a presença de febre (Berezin, 2010). Tosse e desconforto respiratório com taquipneia associado a presença de ruídos adventícios na ausculta pulmonar como sibilância ou estertoração definiram as Infecções Respiratórias Inferiores (IVAI). Optou-se pelo uso de antibiótico para as IVAI de provável origem bacteriana, com febre de frequência e intensidade mais importante e confirmada ou não com achados radiológicos como consolidação, aerobroncograma, derrame pleural e pneumatoceles (Carvalho, 2010).

Episódios de diarreia foram definidos como três ou mais evacuações liquidas acompanhadas ou não de febre e vômitos em período de 24 horas (Koser et al., 2003). As parasitoses foram confirmadas por exame parasitológico da amostra de fezes pelo método de Hoffman, ou presumidas por relato materno de ocorrência de prurido anal intenso ou eliminação de parasitas nas fezes.

\section{Antropometria}

A avaliação da evolução da estatura foi realizada mensalmente e o peso, mensurado quinzenalmente, pela manhã, antes de ser servido o café da manhã, e foi utilizada a média aritmética das duas medidas para o cálculo de incremen- 
to mensal. A curva de referência utilizada foi da OMS (2006) (WHO, 2005). A subnutrição foi definida como grave quando qualquer índice de avaliação antropométrica $(\mathrm{P} / \mathrm{I}, \mathrm{E} / \mathrm{I}$, peso para estatura: $\mathrm{P} / \mathrm{E}$ ou índice de massa corporal para idade $\left(\mathrm{Kg} / \mathrm{m}^{2}\right.$ : IMC/I) se encontrou $<-3$ escores $\mathrm{z}$, moderada quando qualquer desses índices se encontrou entre -3 e -2 escore $z$, e leve para aqueles entre - 2 e -1 .

\section{Intervenção}

As crianças receberam suplementação de vitamina C, A, D, E e complexo $\mathrm{B}$ nas doses recomendadas segundo Dietary Reference Intake (DRI), conforme faixa etária (Food and Nutrition Board, 2005). As crianças de 6 a 24 meses receberam dose profilática de ferro, de 1 a $2 \mathrm{mg} / \mathrm{kg} /$ dia, conforme recomendação da Sociedade Brasileira de Pediatria (2012), micronutriente que era temporariamente suspenso na vigência de febre ou uso de antibióticos. A suplementação de zinco foi feita na forma de quelado em aminoácido metionina, nas doses recomendadas para as faixas etárias segundo as RDA (Recommended Dietary Allowance) (Cozzolini, 2007). No momento da admissão os pacientes acima de 12 meses receberam medicação para erradicação de helmintos e protozoários, independentemente de história clínica ou exames laboratoriais positivos.

As crianças receberam cinco refeições diárias com alimentos da dieta habitual das famílias atendidas e que poderiam ser adquiridos ou encontrados por essas nos locais que normalmente frequentam. A alimentação era servida em quantidade que permitia cobrir $100 \%$ da recomendação de ingestão proteica e $70 \%$ das necessidades energéticas em cardápio, variado com proteína de alto valor biológico (carnes, ovos e leite), além de alcançar oferta recomendada de fibras para a faixa etária segundo DRI (Food..., 2005). A família era orientada para oferecer mais duas refeições em domicílio.

As crianças participavam de oficinas de educação nutricional de acordo com a prontidão psicomotora e cognitiva com o objetivo de enfrentarem os problemas de alimentação. Seu conteúdo visava o conhecimento das variedades de frutas, legumes e verduras; o desenvolvimento neuropsicomotor; a melhoria da relação entre a criança e os alimentos; o desenvolvimento da palatibilidade e promoção do desenvolvimento de bons hábitos alimentares. Às famílias também eram oferecidas oficinas semanais de educação nutricional para o conhecimento de novos alimentos, estímulo para realizar novas formas de preparo e formação de bons hábitos alimentares (Seminário Internacional... 2008). Fóruns e oficinas de artesanato eram oferecidos como espaço para convivência e fortalecimento do vínculo com a instituição e para ampliação de suas redes sociais.

Para avaliação do nível socioeconômico e para o diagnóstico de vulnerabilidade utilizou-se questionário específico (Wanderley, 2006).

\section{Análise estatística}

Trata-se de um estudo clínico longitudinal prospectivo de 57 crianças de 3 a 55 meses de ambos os sexos com diagnóstico de subnutrição primária e que 
foram submetidas ao tratamento em regime de hospital-dia em período não inferior a seis meses (2009-2012).

Foi realizada análise descritiva dos dados, utilizando média e mediana com desvio padrão para as variáveis contínuas e frequência para variáveis categóricas. Foi realizado teste de Kolmogorov-Smirnov para a verificação de normalidade da distribuição das variáveis contínuas. Utilizou-se teste $t$ de Student para comparação de médias das variáveis de distribuição normal e o teste de Mann-Whitney, para variáveis de distribuição não normal (teste não paramétrico).

Foi realizada análise univariada entre o desfecho incremento de estatura para idade e incremento de IMC para idade e as variáveis socioeconômicas, ambientais e de saúde da criança para a pré-seleção de variáveis, utilizando-se como ponto de corte $\mathrm{o}$ valor de $\mathrm{p}<0,2$. Essa fase da análise foi utilizada para identificar as variáveis que deveriam ser utilizadas na análise de regressão logística. $\mathrm{Na}$ análise multivariada utilizou-se o Modelo de Regressão Linear Multivariado, no programa estatístico SPSS, selecionando as variáveis que se associaram ao desfecho incremento de estatura para idade com nível de significância estatística $<0,05$.

Este estudo foi aprovado pelo Comitê de Ética em Pesquisa da Universidade Federal de São Paulo sob a inscrição no ${ }^{0}$ 1810/11.

\section{Resultados}

O tempo médio de tratamento foi de 20,96 meses com mínimo de seis e máximo de 44 meses. O momento da introdução da alimentação complementar foi em média com 171,82 dias de vida, variando de 89 a 358 dias. Setenta e quatro por cento (42) das crianças não frequentavam creches ou centros de educação infantil no momento da admissão, e 14\% (8) apresentavam irregularidade na situação vacinal, a maioria com falta de documento comprobatório (carteira de vacina ou resumo de alta hospitalar/maternidade). Vinte e uma crianças $(36,7 \%)$ tinham histórico anterior de internação hospitalar em nível terciário. $\mathrm{Na}$ admissão, $19(33,3 \%)$ crianças apresentavam valores em algum dos quatro índices antropométricos utilizados $(\mathrm{E} / \mathrm{I}, \mathrm{IMC} / \mathrm{I}, \mathrm{P} / \mathrm{I}$ ou $\mathrm{E} / \mathrm{I})<-3$ escores $\mathrm{z}$. A estatura das mães foi $\leq 155 \mathrm{~cm}$ em $54,9 \%$ das vezes. Os domicílios das famílias em $45,3 \%$ das vezes se localizavam em favelas no entorno do CREN; $3,5 \%$, em conjuntos habitacionais; e $2 \%$, em loteamentos populares; o restante das famílias moravam em bairros. O tipo de material utilizado para a construção do domicílio foi de madeira ou misto em $17 \%$ das residências, sendo o restante de alvenaria com ou sem acabamento. O acesso à água encanada foi encontrado em $100 \%$ das famílias, mas o destino do esgoto para a rede geral foi encontrado em 82,4\% dos domicílios. Situação de reclusão/conflito com a lei, presença de dependente químico e alcoolismo de algum membro da família foram encontradas em $19,3 \%, 26,3 \%$ e $21,1 \%$, respectivamente, nas famílias estudadas. A renda familiar per capita variou de 40,00 a 750,00 reais (taxa de câmbio em 24.4.2013: US\$ $\mathrm{l}=\mathrm{R} \$ 2,02)$ e $10,5 \%$ das famílias se encontravam abaixo da linha de pobreza. 
Tabela 1 - Características maternas e dos pacientes na admissão

\begin{tabular}{lcc}
\hline Características & $\begin{array}{c}\text { No ou Média }^{\text {(N.57) }} \\
\text { Sexo masculino }\end{array}$ & $\begin{array}{c}\text { \% ou DP } \\
\text { (N.57) }\end{array}$ \\
\hline Idade gestacional <37 semanas & 10 & 54.4 \\
Peso ao nascer (gramas) & 2577.28 & 17.5 \\
Baixo peso ao nascer & 21 & 573.77 \\
Em aleitamento materno na admissão & 29 & 36.8 \\
Anemia (Hb <11g/dl) ${ }^{1}$ na admissão & 17 & 50.9 \\
Idade na admissão (meses) & 22.64 & 12.11 \\
Hemoglobina na admissão (g/dl) & 11.60 & 1.03 \\
Número de consultas de pré-natal ${ }^{2}$ & 6.8 & 2.25 \\
Parto vaginal & 35 & 61.4 \\
Uso de tabaco na gestação & 12 & 21.1 \\
Estatura da mãe (cm) ${ }^{3}$ & 154.14 & 6.68 \\
Escolaridade materna: & & 1.9 \\
$\quad$ Não alfabetizada & 231.53 & 30.8 \\
$\quad$ Fundamental incompleto & 2.25 & 11.5 \\
$\quad$ Fundamental completo & 25 & 48.9 \\
\hline Eńmensino médio & 1.52 \\
\hline
\end{tabular}

${ }^{1} \mathrm{Hb}$, hemoglobina; ${ }^{2}$ Número mínimo de consultas ao pré-natal recomendado pelo Ministério da Saúde do Brasil = 6 (Ministério da Saúde, 2005); ${ }^{3}$ Valor médio equivalente ao percentil 5 da referência NCHS (2000).

A maioria das crianças subnutridas era do sexo masculino (Tabela 1), e nasceram a termo $(82,5 \%)$, mas com peso médio insuficiente; e mais do que um terço da amostra apresentou baixo peso ao nascer e anemia. As mães apresentaram um número de consultas de pré-natal adequado em média e a maioria teve parto vaginal. Um pouco menos de um quarto fumou durante a gestação. A média de estatura materna correspondeu ao percentil 5 de acordo com a referência NCHS (2000). Mais de $60 \%$ das mães não completaram o ensino fundamental ou eram analfabetas. 
A baixa estatura foi o distúrbio nutricional de maior gravidade com a média de $\mathrm{E} / \mathrm{I}$ de $-2,70$ escores $\mathrm{z}$ no ingresso ao hospital-dia. Da mesma forma, a média de incremento de estatura para idade foi também a mais elevada com 0,43 escores $\mathrm{z}$ em relação aos outros índices antropométricos, as formas mais graves de baixa estatura tiveram os maiores incrementos (Figura 2a). A média de IMC/I na admissão foi de $-0,58$ escores $\mathrm{z}$, com incremento de 0,28 escores $\mathrm{z}$ (Figura $2 \mathrm{~b}$ ). A média do percentual de faltas ao tratamento foi de $22,4 \%$, variando de $2,2 \%$ a $85,8 \%$.

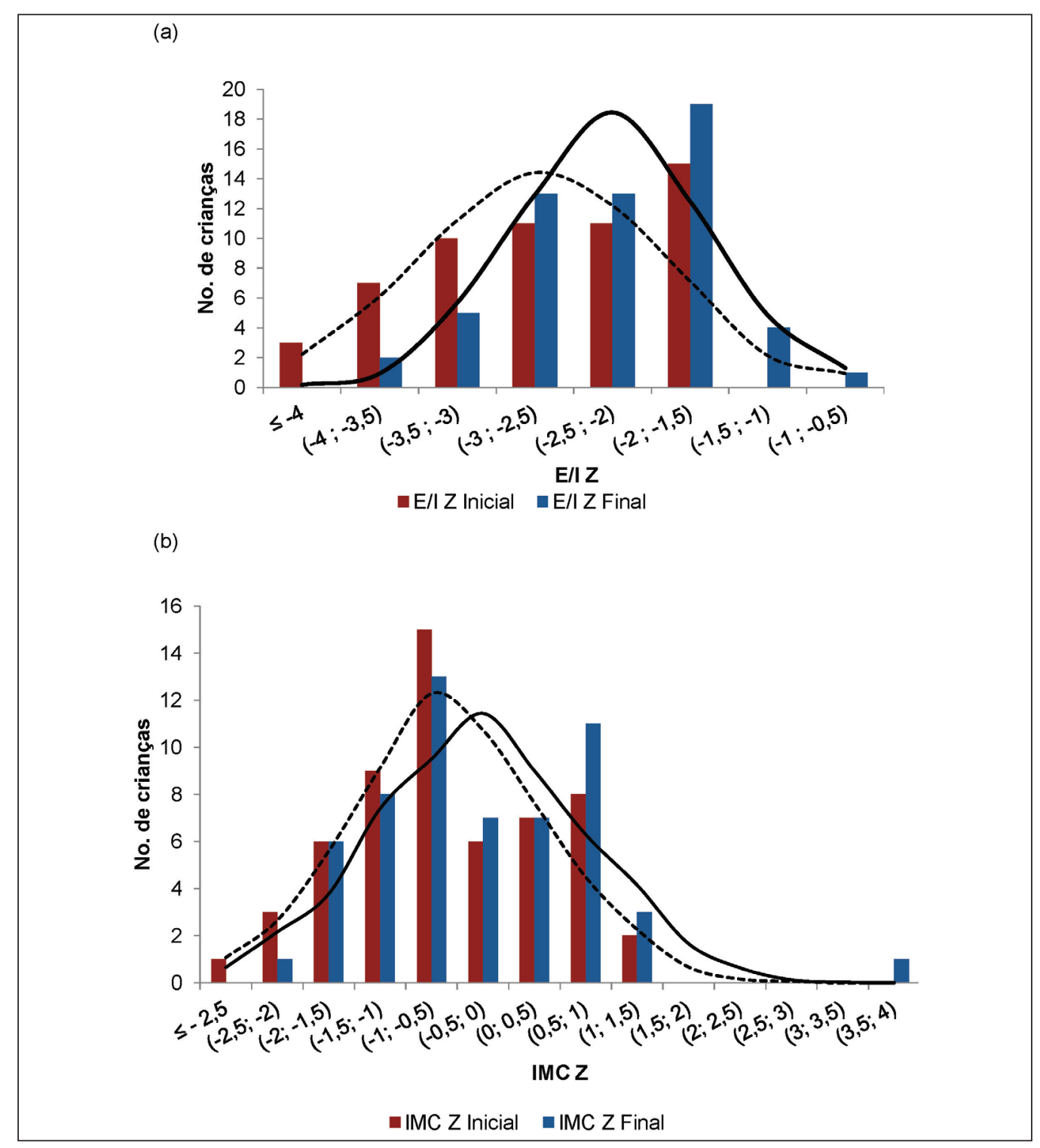

Figura 2 - Evolução do índice (a) estatura para idade (E/I) em escore z (b) e Índice de massa corporal para idade (IMC/I) em escore z: na admissão $(-$, a) e ao final do estudo $(-, \boldsymbol{a})$ de 57 crianças em tratamento em hospital-dia (CREN). 
As Infecções das Vias Aéreas Superiores (IVAS) foram as mais frequentes, de origem bacteriana ou viral, descritas de acordo com a intervenção terapêutica como com ou sem o uso de antibiótico (atb) respectivamente (Tabela 2). As infecções de trato respiratório alto de provável origem bacteriana foram significantemente mais frequentes nos pacientes com subnutrição na forma clínica grave. O mesmo ocorreu para as Infecções de Vias Aéreas Inferiores (IVAI) de origem viral que também se mostraram significantemente mais constantes nesse grupo, expressas por quadros de sibilância. A frequência de infecção de trato respiratório baixo com provável origem bacteriana em toda a amostra foi de 0,79 episódios/criança, não havendo diferença entre as formas clínicas de subnutrição. A média de doenças gastrointestinais, virais ou bacterianas, identificadas por episódios de diarreia e/ou vômitos acompanhados ou não de febre, foi de 2,28 por criança; já a média de episódios de parasitoses intestinais, presumidas ou constatadas laboratorialmente, foi de 0,68 por criança. Não houve diferença na prevalência de doenças gastrointestinais (bacterianas, virais ou parasitarias) entre as crianças com subnutrição grave e moderada (Tabela 2). Quando se dicotomizou a amostra em faixa etária, utilizando a mediana da idade na admissão, as crianças com menor idade na admissão tiveram maior número de episódios de infecção respiratória, de trato respiratório alto ou baixo, de etiologia viral ou bacteriana (Tabela 3 ).

Em 26 exames de protoparasitológico foram identificados algum tipo de parasita durante o período de tratamento, com positividade nos exames semestrais variando de $7 \%$ a $10,5 \%$ da amostra coletada. A Giardia lamblia foi o parasita mais frequente, em $57 \%$ dos exames positivos, enquanto Enterobius vermiculares foi encontrado em 15\% dos PPF positivos.

Tabela 2 - Intercorrências clínicas e infecciosas de acordo com o estado nutricional na admissão

\begin{tabular}{lccccc}
\hline & \multicolumn{4}{c}{ Número de episódios/criança } \\
\cline { 2 - 5 } & \multicolumn{2}{c}{$\begin{array}{c}\text { Subnutrição } \\
\text { grave (19) }\end{array}$} & $\begin{array}{c}\text { Subnutrição } \\
\text { moderada (38) }\end{array}$ & Valor \\
\cline { 2 - 5 } & Media & DP & Media & Media & de p \\
\hline IVAS $^{1}$ sem uso de atb ${ }^{3}$ & 7.00 & 4.64 & 5.2 & 3.53 & 0.155 \\
IVAS com uso de atb $^{\text {IVAI }}{ }^{2}$ com uso de atb & 4.42 & 4.07 & 2.3 & 2.53 & $0.035^{*}$ \\
Diarreia aguda & 0.84 & 0.89 & 0.7 & 1.05 & 0.500 \\
Parasitose intestinal & 3.36 & 3.71 & 1.7 & 1.42 & 0.075 \\
IVAI sem uso de atb & 1.10 & 1.96 & 0.47 & 0.82 & 0.420 \\
(Broncoespasmo) & 5.15 & 4.46 & 2.97 & 3.57 & $0.034^{*}$ \\
\hline
\end{tabular}

*Significância $\mathrm{p}<0$, 05 Mann-Whitney Test.

${ }^{1}$ IVAS, infecção de vias aéreas superiores; ${ }^{2}$ IVAI, infecção de vias aéreas inferiores; ${ }^{3}$ atb, antibiótico. 
Tabela 3 - Intercorrências clínicas e infecciosas de acordo com idade na admissão

\begin{tabular}{|c|c|c|c|c|c|}
\hline & \multicolumn{5}{|c|}{ Número de episódios/criança } \\
\hline & \multicolumn{2}{|c|}{$\begin{array}{c}\leq 19 \text { meses } \\
(29)\end{array}$} & \multicolumn{2}{|c|}{$\begin{array}{l}>19 \text { meses } \\
(28)\end{array}$} & \multirow{2}{*}{$\begin{array}{l}\text { Valor } \\
\text { de } \mathrm{p}\end{array}$} \\
\hline & Média & $\mathrm{DP}$ & Média & Média & \\
\hline IVAS $^{1}$ sem uso de atb $^{3}$ & 7.62 & 4.57 & 3.92 & 2.01 & $0.001^{*}$ \\
\hline IVAS com uso de atb & 3.72 & 3.60 & 2.32 & 2.72 & $0.034^{*}$ \\
\hline$|V A|^{2}$ com uso de atb & 1.13 & 1.12 & 0.42 & $0.68)$ & $0.008^{*}$ \\
\hline Diarreia aguda & 2.95 & 3.19 & 1.57 & 1.28 & 0.053 \\
\hline Parasitose intestinal & 0.93 & 1.66 & 0.42 & 0.83 & 0.308 \\
\hline $\begin{array}{l}\text { IVAI sem uso de atb } \\
\text { (Broncoespasmo) }\end{array}$ & 5.20 & 4.20 & 2.14 & 3.26 & $0.001^{*}$ \\
\hline
\end{tabular}

*Significância $p<0,05$ Mann-Whitney Test.

${ }^{1}$ IVAS, infecção de vias aéreas superiores; ${ }^{2}$ IVAI, infecção de vias aéreas inferiores; ${ }^{3}$ atb, antibiótico.

Tabela 4 - Regressão linear múltipla com incremento de estatura como variável dependente

\begin{tabular}{|c|c|c|c|c|c|c|}
\hline \multirow[b]{2}{*}{ Constante } & \multirow[t]{2}{*}{$\begin{array}{l}\text { Coeficiente } \\
\text { de Person } \\
\text { (R) }\end{array}$} & \multirow[t]{2}{*}{$\begin{array}{l}\text { Valor } \\
\text { de } p\end{array}$} & \multirow{2}{*}{$\begin{array}{c}\text { Coeficiente } \\
\text { regressão } \\
\text { estandartizada } \\
(\beta) \\
\end{array}$} & \multirow{2}{*}{$\begin{array}{l}\text { Valor } \\
\text { de } p\end{array}$} & \multicolumn{2}{|c|}{$\begin{array}{c}\text { Intervalo de } \\
\text { confiança } 95 \%\end{array}$} \\
\hline & & & & & 1.643 & 4.926 \\
\hline $\begin{array}{l}\text { Estatura para idade na } \\
\text { admissão }\end{array}$ & -0.581 & 0.000 & -0.414 & 0.000 & -0.399 & -0.138 \\
\hline IMC/idade na admissão ${ }^{1}$ & 0.266 & 0.046 & & & & \\
\hline Hemoglobina na admissão & -0.473 & 0.000 & -0.381 & 0.002 & -0.249 & -0.059 \\
\hline Hematócrito na admissão & -0.329 & 0.013 & & & & \\
\hline Idade na admissão & -0.387 & 0.003 & & & & \\
\hline Tempo de tratamento & -0.384 & 0.003 & & & & \\
\hline $\begin{array}{l}\text { Média de faltas ao } \\
\text { tratamento/ano }\end{array}$ & -0.135 & 0.158 & -0.225 & 0.029 & -0.259 & -0.014 \\
\hline $\begin{array}{l}\text { Episódios de parasitose } \\
\text { intestinal }\end{array}$ & 0.225 & 0.048 & & & & \\
\hline $\begin{array}{l}\text { Episódios de diarreia } \\
\text { aguda }\end{array}$ & 0.119 & 0.189 & & & & \\
\hline $\begin{array}{l}\text { Número de consultas no } \\
\text { pré-natal }\end{array}$ & 0.197 & 0.179 & & & & \\
\hline Estatura materna & -0.323 & 0.021 & & & & \\
\hline Escolaridade materna & -0.124 & 0.009 & & & & \\
\hline Número de filhos & 0.191 & 0.158 & & & & \\
\hline Renda familiar per capita & -0.319 & 0.000 & -0.319 & 0.003 & -0.439 & -0.092 \\
\hline
\end{tabular}

${ }^{1} \mathrm{IMC}$, índice de massa corpórea $\left(\mathrm{kg} / \mathrm{m}^{2}\right)$. 
$\mathrm{Na}$ análise de regressão linear múltipla com incremento da estatura como variável dependente, o índice de estatura para idade na admissão em escore z, o nível de hemoglobina em momento próximo da admissão, a renda familiar per capita e o percentual de faltas ao tratamento foram fatores preditivos $(\mathrm{p}<0,05)$ com correlação inversa e significativa. Para todas as outras variáveis, os coeficientes $\beta$ indicaram quase nenhuma influência sobre o incremento do índice estatura para idade (Tabela 4).

\section{Discussão}

O CREN, adaptado à realidade de uma grande metrópole como São Paulo, atende famílias pobres com alta taxa de vulnerabilidade social, baixa escolaridade, com problemas de drogadição e com prevalências de conflito com a lei que chegam a um quarto das famílias. E por isso, tem como meta de atendimento não apenas a recuperação nutricional, mas também a intervenção social. Os estudos existentes sobre a recuperação nutricional em CRN preferem normalmente utilizar como critério de alta o índice $\mathrm{P} / \mathrm{E}$, além de apresentarem tempo de tratamento inferior ao do nosso estudo. O CREN utiliza o índice E/I como padrão ideal de recuperação nutricional. A baixa estatura na infância é reconhecidamente um fator de risco para as doenças crônicas não comunicáveis na vida adulta, como diabetes, hipertensão arterial, dislipidemias e obesidade, acarretando prejuízos na qualidade de vida desses indivíduos e nos cofres da saúde pública. A importância de uma intervenção adequada, que não almeje exclusivamente a normalização do $\mathrm{P} / \mathrm{E}$, mas que resulte em incremento de $\mathrm{E} / \mathrm{I}$, implica tempo de tratamento maior, mas é garantia para saúde em longo prazo. Pacientes que receberam tratamento em hospital-dia no CREN, em seguimento médio de dois anos após alta por recuperação, apresentaram composição corporal com proporções adequadas de massa magra e massa gorda e manutenção de hábitos alimentares adequados (Das Neves et al., 2006), evidenciando os efeitos duradouros da intervenção.

\section{Infecções respiratórias, diarreia e parasitose intestinal}

A relação bidirecional entre infecção e subnutrição tem sido reconhecida há anos. Ingestão inadequada de proteínas, energia e micronutrientes aumenta a suscetibilidade e retarda a recuperação de processos infecciosos. Por sua vez, a infecção aumenta a demanda de nutrientes, ao mesmo tempo que diminui ingestão por redução do apetite. As consequências no estado nutricional desse ciclo vicioso ficam mais evidentes na infância, onde boa parte da demanda de substrato está endereçada ao processo de crescimento (Rodriguez et al., 2011).

As IVAS são responsáveis por $40 \%$ a $60 \%$ das consultas pediátricas no continente americano e constituem o principal motivo para o uso de antibiótico na criança. Inversamente proporcional à idade estima-se que crianças abaixo de cinco anos apresentem entre 4 e 14 episódios de IVAS/ano. As características anatômicas do trato respiratório superior, somadas às características imunológicas fazem esse grupo etário ser mais suscetível às infecções (Berezin, 2010). Nosso 
grupo de estudo não apresentou prevalência maior do que a descrita na literatura, mesmo quando as IVAS foram agrupadas em etiologia viral e bacteriana.

Nas Américas, aproximadamente cem mil mortes por ano são causadas por infecções respiratórias em crianças menores de um ano, e o Brasil contribui com 40\% dessas mortes (Rodriguez et al., 2011). Estudo nacional encontrou uma incidência $80 \%$ mais elevada de pneumonia em crianças que viviam em áreas com condições socioeconômicas desfavoráveis, indicando que o aumento da exposição a agentes virais e bacterianos em condições de superlotação e promiscuidade pode contribuir para o aumento do risco de infecções mais invasivas do trato respiratório (Thorn et al., 2011). Em nosso estudo, os pacientes que tinham maior comprometimento nutricional, em qualquer um dos índices antropométricos utilizados, apresentaram infecções de trato respiratório de maior gravidade e de características mais invasivas, traduzidos por uso de antibiótico e em maior frequência. O mesmo ocorreu para as crianças mais novas e $49,1 \%$ das crianças apresentaram pelo menos um episódio de pneumonia durante o estudo. Os episódios de broncoespasmos foram frequentes em nossa amostra e se associaram à idade e à gravidade da subnutrição. Quanto mais jovem e mais grave a baixa estatura, maior o número de episódios de broncoespasmo.

Estudos em crianças de zero a dois anos moradoras de favelas na Grande São Paulo apresentaram risco de ocorrência de diarreia 15 vezes maior quando comparado àquelas que vivem em condições adequadas de habitação e saneamento (Paz et al., 2012). Em favelas de Salvador encontrou-se prevalência de 2,8 episódios de diarreia por criança por ano, e associação positiva de risco para doença diarreica com o estado nutricional, mesmo para as formas leves de comprometimento de crescimento linear $(\mathrm{E} / \mathrm{I}<\mathrm{l}$-escore $\mathrm{z})$ onde crianças com baixa estatura eram quase três vezes mais propensas a ter mais de três episódios de diarreia por ano do que o grupo sem subnutrição (Melo et al, 2008). Nosso estudo apresentou prevalência semelhante, com média de 3,3 episódios de diarreia por criança nos casos graves de subnutrição, no entanto cabe ressaltar que os estudos existentes utilizam o relato de cuidadores, informação que depende diretamente do entendimento e da capacidade de reconhecimento da doença diarreica pelo cuidador (Melo et al., 2007). Em nosso estudo a maior parte dos dados foi coletada por observação direta das eliminações do paciente por profissional da saúde, o que aumenta a acurácia da informação. Outro dado é que em nossa amostra mais da metade das crianças estava em aleitamento materno. Os efeitos benéficos do aleitamento materno e seu fator protetor contra as infecções intestinais são vastamente documentados, principalmente em crianças abaixo dos 24 meses (Lamberti et al., 2011).

Os danos que os enteroparasitas podem causar a seus portadores incluem obstrução intestinal, subnutrição, anemia por deficiência de ferro, quadros de má absorção, diarreia e atraso no crescimento e desenvolvimento infantil (Matos et al., 2008). As manifestações clínicas são usualmente proporcionais à carga parasi- 
tária albergada pelo indivíduo. Entre os enteroparasitas a Giardia lamblia é o protozoário mais frequentemente encontrado, com sua prevalência estimada em $20 \%$ a $30 \%$ nos países em desenvolvimento, e $2 \%$ a $5 \%$ nos países desenvolvidos (Silva et al., 2009). No município de São Paulo ocorreu redução expressiva na prevalência das parasitoses em geral. Na década de $1980,31 \%$ das crianças ( $<5$ anos) apresentavam uma ou mais espécies de parasitas intestinais, sendo o Ascaris lumbricoides o mais frequente, seguido pela Giardia lamblia e Trichiurus trichiura. Já na década de 1990 outro estudo com mesma metodologia encontrou $11 \%$ das crianças abaixo de 60 meses com algum tipo de parasita intestinal, sendo a Giardia lamblia o parasita mais encontrado (5,5\%) (Ferreira et al., 2000). Em nossa amostra o parasita mais frequente foi a Giardia lamblia, mas não encontramos correlação significativa entre a presença de parasitose intestinal e o desfecho final da recuperação nutricional. A prescrição de vermífugos no momento da admissão e a sistemática lavagem das mãos com a presença dos responsáveis no momento inicial do tratamento diário como medida terapêutica e educativa pode ter reduzido a prevalência das parasitoses em nossa amostra e seu impacto no crescimento.

Sinteticamente, em nosso estudo a prevalência de doenças infecciosas e parasitárias não se mostrou superior aos dados encontrados na literatura, em nível nacional ou regional, e apesar de as infecções e parasitoses gastrointestinais terem relevância estatística marginais não afetaram de forma significativa o incremento da estatura das crianças. Cabe ressaltar ainda que um dos aspectos que diferenciam nossa amostra é que os pacientes estavam sob intervenção, com diagnóstico e medidas prescritivas precoces, em uso de suplemento de micronutrientes (zinco e vitamina A, entre outros) e sob suporte nutricional, minimizando os efeitos deletérios dos processos infecciosos e ao mesmo tempo promovendo recuperação nutricional.

Esses achados mostram a importância do tratamento em hospital-dia para minimizar o impacto das infecções no crescimento. A Figura 3 ilustra o ganho de peso de uma criança em tratamento no hospital-dia no CREN em comparação com uma criança da Guatemala em acompanhamento na comunidade. Pode-se observar que o tratamento no CREN permitiu uma aceleração no ganho de peso da criança de forma que esse atingisse o percentil 10 da curva de referência (NCHS, 1977), enquanto a criança guatemalteca afasta-se da curva de referência ao longo do tempo de acompanhamento devido ao impacto das infecções e alimentação inadequada.

\section{Estado nutricional e anemia}

As crianças que apresentaram os piores índices de E/I na admissão tiveram os maiores incrementos de E/I, semelhante aos resultados de Vieira et al. (2010) e Fernandes et al. (2011) indicando um fenômeno compensatório, de mecanismo ainda desconhecido. A idade na admissão se mostrou significativa em análise univariada, uma vez que quanto mais jovem a criança iniciava o tratamento, maior a chance de recuperação, porém essa significância desapareceu no modelo de regressão múltipla. 
(a)

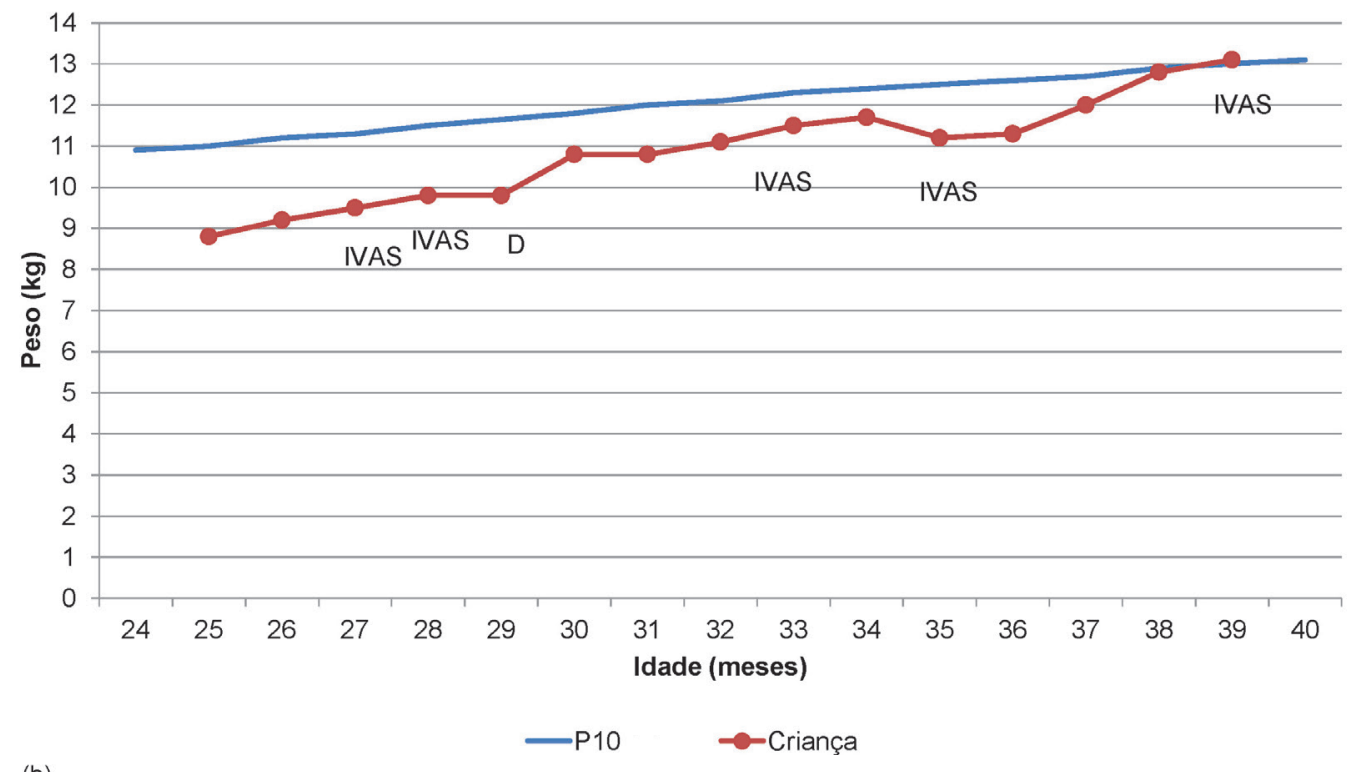

(b)

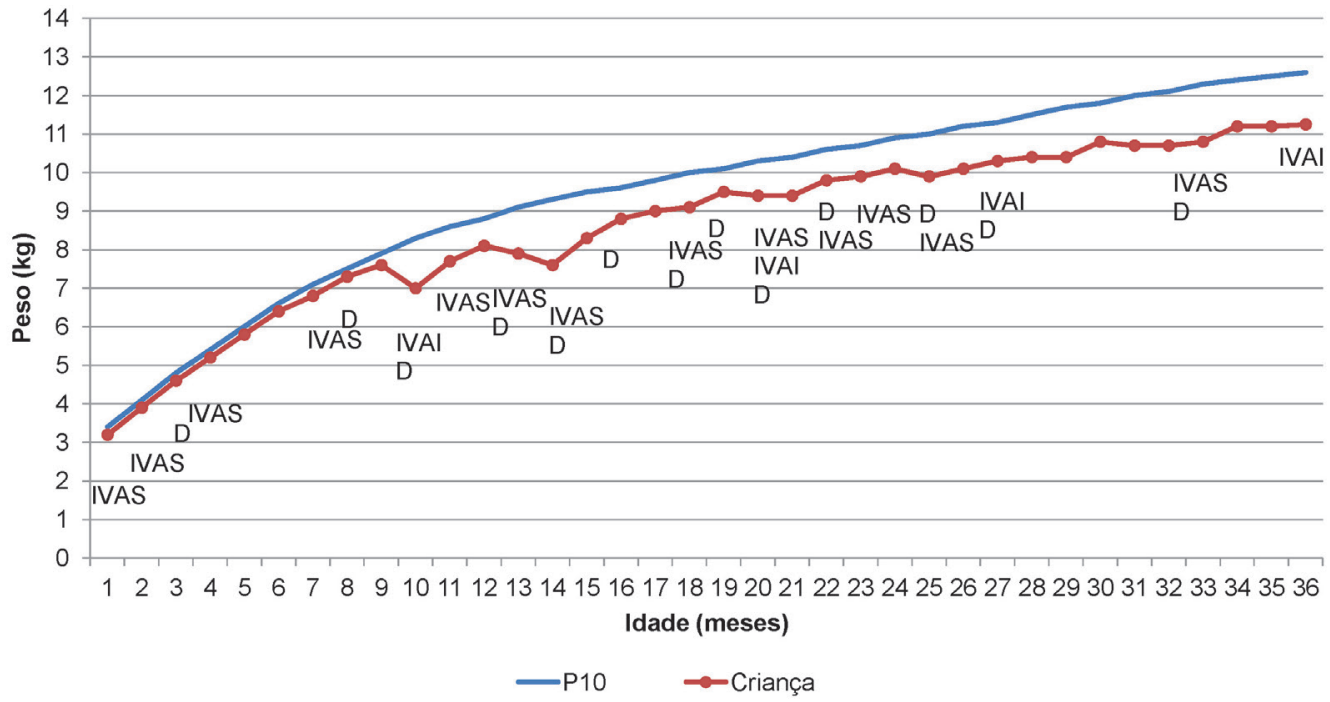

Figura 3 - Exemplos de relação temporal entre infecção e ganho de peso em crianças subnutridas (a) em tratamento no hospital-dia do Centro de Recuperação e Educação Nutricional (Sawaya, 2006) e (b) em comunidade na Guatemala (Mata, 1976 modificado). IVAS: infecção de vias aéreas superiores; IVAI: infecção de vias aéreas inferiores; D: diarreia.

Embora estudos demonstrem correlações positivas entre deficiência de ferro e atraso no crescimento, poucos estudos estão disponíveis na literatura sobre deficiência de ferro, velocidade de crescimento e os efeitos sobre o crescimento após recuperação da anemia, assim como após o tratamento com ferro. A evidência que a suplementação de ferro possa exercer impacto sobre o cresci- 
mento ainda permanece contraditória (Rivera et al., 2003; Ramakrishnan et al., 2004). A anemia afeta 1,62 bilhão de pessoas no mundo, o que corresponde a $24,8 \%$ da população mundial. Porém, uma prevalência muito maior $(47,4 \%)$ é encontrada em crianças de zero a cinco anos (WHO, 2008). No Brasil, estudos regionais com crianças em diferentes faixas etárias apontam prevalências que variam de $28,7 \%$ a $77,5 \%$, (media $=53 \%$ ), sendo as regiões de maior prevalência a Norte e a Centro-Oeste (Jordão et al., 2009). Em nosso estudo os baixos níveis de hemoglobina foram preditivos para um maior incremento na estatura final. Isso mostra que, de forma semelhante à criança com maior gravidade do ponto de vista antropométrico, aquela com presença de menor nível de hemoglobina também apresentou maior velocidade de recuperação nas condições de tratamento oferecidas pelo CREN.

\section{Conclusões}

O presente estudo mostrou que o paciente mais vulnerável nutricionalmente, com menores índices de estatura para idade e taxa de hemoglobina na admissão, assim como maior risco socioeconômico de acordo com a renda per capita apresentou maior incremento de E/I.

É digno de nota que um fator fortemente associado à recuperação de $\mathrm{E} / \mathrm{I}$ foi a maior frequência ao tratamento. Nessas condições observou-se um impacto menor das infecções e parasitoses, fatores classicamente associados à subnutrição. Esses resultados mostram a importância do tratamento em hospital-dia para crianças com subnutrição moderada/grave para a saúde em longo prazo.

Nesse sentido, acreditamos ser de grande importância para a erradicação da baixa estatura no Brasil a criação de portaria para o atendimento à criança com subnutrição primaria em hospital-dia em locais de elevada vulnerabilidade social.

\section{Referências}

BEREZIN, E. M. Infecções de vias aéreas superiores. In: LOPEZ, F. A. Tratado de Pediatria Sociedade Brasileira de Pediatria. Barueri: Manole, 2010. p.1175-9.

BLACK, R. E. et al. Maternal and child undernutrition: global and regional exposures and health consequences. Lancet, v.371, p.243-60, 2008.

CARVALHO, C. M. C. N. Infecções de vias aéreas inferiores. In: LOPEZ, F. A. Tratado de Pediatria Sociedade Brasileira de Pediatria. Barueri: Manole, 2010. p.1169-74. COZZOLINO, S. M. F. Zinco. In: Biodisponibilidade de nutrientes. Barueri: Manole, 2007. p.560.

DAS NEVES, J. et al. Malnourished children treated in day-hospital or outpatient clinics exhibit linear catch-up and normal body composition. J. Nutr., v.136, p.648-55, 2006.

FARHAT, C. K.; FARIA, S. M. Repercussões infecciosas da desnutrição energético-proteica. In: NOBREGA, F. J. Distúrbios da nutrição. Rio de Janeiro: Revinter, 1998. p.203-10. 
FERNANDES, M. B. F. et al. A 15- year study on the treatment of undernourished children at a nutrition rehabilitation centre (CREN), Brazil. Public Health Nutrition, n.3, p.1-9, 2011.

FERREIRA, U. M. et al. Tendência secular das parasitoses intestinais na infância na cidade de São Paulo (1984-1996). Rev. Saúde Publ., v.34, p.73-82, 2000.

FOOD AND NUTRITION BOARD. Dietary reference intakes for energy, carbohydrate, fiber, fat, fatty acids, cholesterol, protein, and amino acids (Macronutrients). The National Academy Press, 2005.

FRISANCHO, A. R. Antropometric classification. Anthropometric standarts for the assessment of growth and nutritional status. Ann Arbor: University of Michigan Press, 1993. p.31-6.

FRONGILLO JUNIOR, E. A. et al. Socioeconomic and demographic factors are associated with worldwide patterns of stunting and wasting of children. J. Nutri., p.57-73, 1997.

JORDÃO, R. E. et al. Prevalence of iron-deficiency anemia in Brazil: a systematic review. Rev. Paul Pediatr., v.27, n.1, p.90-8, 2009.

KOSEK, M. et al. The global burden of diarrhea disease, as estimated from studies published between 1992 and 2000. Bull. World Health Organ., v.81, p.197-204, 2003.

LAMBERTI et al. Breastfeeding and the risk for diarrhea morbidity and mortality. BMC Public Health, v.11, n.3, p.S15, 2011.

MARTORELL, R. et al. Poverty and stature in children. In: WATERLOW, J. C. (Ed.) Linear growth retardation in less developed countries. New York: Raven Press; 1998. p.57-73.

MATA, L. J. et al. Breast-feeding, weaning and the diarrheal syndrome in a Guatemalan Indian village. Acute diarrhea in childhood. Ciba Found Symp., v.42, p.311-38, 1976.

MATOS. S. M. A. et al. Giardia duodenalis infection and anthropometric status in preschoolers in Salvador, Bahia, Brazil. Cad. Saúde Pública, v.24, n.7, p.1527-35, 2008.

MELO, M. C. N. et al. Incidence of diarrhea: poor parenteral recall ability. Braz. J. Infect Dis., v.11, n.6, p.571-4, 2007.

. Incidence of diarrhea in children living in urban slums in Salvador, Brazil.

Braz. J. Infect. Dis., v.12, n.1, 2008.

MINISTÉRIO DA SAUDE (BRASIL), Secretaria de Atenção à Saúde, Departamento de Ações Programáticas Estratégicas Pré-natal e Puerpério: atenção qualificada e humanizada - manual técnico - Brasília: Ministério da Saúde,2005.

NATIONAL CENTER FOR HEALTH STATISITCS. Growth curves for children birth to 18 years: United States Department of health Education and Welfare, vital and Health Statistics. 1977 - Series $11 \mathrm{nb}$ 165b.

NATIONAL CENTER FOR HEALTH STATISTIC. Growth curves 2000. Disponível em: <http://www.cdc.gov/growthchards>.

PAZ, M. G. A. et al. Prevalência de diarreia em crianças e condições de saneamento e moradia em áreas periurbanas de Guarulhos, SP. Rev. Bras. Epidemiol., v.15, n.1, p.188$97,2012$.

PESQUISA de ORÇAMENTO FAMILIARES 2008-2009. Antropometria e análise do estado nutricional de crianças e adolescentes no Brasil. IBGE. Rio de Janeiro; 2010. 
RAMAKRISHNAN, U. et al. Multimicronutrient interventions but not Vitamin A or Iron intervention lone improves child growth: result of 3 meta-analyses. J. Nutr. v.134, p.2592-602, 2004.

RIVERA, J. A. et al. The effect of micronutrient deficiencies on child growth: a review of results from community- based suplemmentation trials. J. Nutr., v.133, p.4010-20, 2003.

RODRIGUEZ, L. et al. Malnutrition and gastrointestinal and respiratory infections in children: a public health problem. Int. J. Environ Res Public Health., v.8, n.4, p.11741205, April 2011.

SAWAYA, A. L. Desnutrição urbana no Brasil em um período de transição. São Paulo: Cortez, 1997. p.161-4.

Políticas públicas: pontos de método e experiências. Estudos Avançados, São Paulo, v.20, n.56, p.131-47, 2006.

SEMINÁRIO INTERNACIONAL. Caminhos da infância e da não violência. II. 2008. Brasília CALIA JD. Texturas e Sabores, o aprendizado nutricional para as crianças de 6 a 24 meses e suas famílias.

SHIMELES, D.; LULSEGED, S. Clinical profile and pattern of infection in Etiopian children with severe protein- energy malnutrition. East. Af. Med. J., v.71, p.264-7, 1994.

SILVA, R. R. et al. Association between nutritional status, environmental and socio-economic factors and Giardia lamblia infections among children aged 6-71 months in Brazil. Transactions of the Royal Society of Tropical Medicine and Hygiene, v.103, p.512-9, 2009.

SOCIEDADE BRASILEIRA DE PEDIATRIA. Departamento Científico de Nutrologia. Anemia ferropriva em lactentes: revisão com foco em prevenção. 2012

TANEJA, G. et al. A study to evaluate the effect of nutritional intervention measures on admitted children in selected nutrition rehabilitation centers of Indore and Ujjain divisions of the state of Madhya Pradesh (India). Indian J. Community Med., v. 37, n.2, p.107-15, 2012.

THORN et al. Pneumonia and poverty: a prospective population-based study among children in Brazil. BMC Infectious Diseases, v.11, p.180, 2011.

VIEIRA, M. F. A. et al. Height and weight gains in a nutrition rehabilitation day-care service. Public Health Nutrition, v.13, n.10, p.1505-10, 2010.

WANDERLEY, M. B. Sistema de informação em gestão social. Estudos Avançadados, São Paulo, v.20, n.56, p.148, 2006.

WORLD HEALTH ORGANIZATION. Management of severe malnutrition: a manual for physicians and others senior health works. Geneva: WHO, 1999.

WHO Anthro 2005 software and macros. Geneva: Switzerland: World Health Organization, 2005. mia.2008

. Worldwide prevalence of anaemia 1993-2005.WHO global database on anae-

WORLD HEALTH STATISTICS, World Health Organization. 2009. Disponível em: <http://www.who.int/whosis/whostat/EN_WHS09_Full.pdf>.

ZAMAN, K. et al. Malnutrition cell-mediated immune deficiency and acute upper respiratory infections in rural Bangladeshi children. Acta Paediatr., v.86, p.923-7, 1997. 
RESUMO - Avaliou-se o impacto de fatores socioeconômicos, maternos, frequência ao tratamento e frequência de infecções, parasitoses e anemia no incremento de estatura para idade (E/I) em crianças (< 5 anos) submetidas a tratamento em hospital-dia no Centro de Recuperação e Educação Nutricional $(n=57)$. Doenças respiratórias superiores foram as mais frequentes com associação positiva com a gravidade da subnutrição ( $\mathrm{p}$ $=0,035)$ e a idade na admissão $(\mathrm{p}=0,001)$. Em análise de regressão múltipla a gravidade da subnutrição, o baixo nível de hemoglobina, menor renda familiar e frequência no serviço foram fatores preditivos $(\mathrm{p}<0,05)$ para maior incremento de E/I. Os achados mostram a importância do tratamento em hospital-dia para o tratamento de crianças subnutridas.

PALAVRAS-CHAVE: Infecção respiratória, Subnutrição, Crianças, Parasitoses, Diarreia.

ABSTRACT - We evaluated the impact of socioeconomic and maternal conditions, treatment frequency and frequency of infections, parasites and anemia in the increment of height for age $(\mathrm{H} / \mathrm{A})$ in children $(<5$ years $)$ undergoing treatment at day-hospital at a Center for Recovery and Nutritional Education $(n=57)$. Upper respiratory infections were the most frequent disease with positive association with the severity of undernutrition $(\mathrm{p}=0.035)$ and age at admission $(\mathrm{p}=0.001)$. In multiple regression analysis, the severity of undernutrition, low hemoglobin level, family income and the low frequency at the service were predictors of increment in stature $(\mathrm{p}<0.05)$. The findings show the importance of treatment in day hospitals for undernourished children.

KErWORDS: Respiratory infection, Undernutrition, Children, Parasitosis, Diarrhea.

Maria Paula de Albuquerque é médica pediatra formada pela Escola Paulista de Medicina da Unifesp, com área de atuação em Nutrologia Pediátrica pela Sociedade Brasileira de Pediatria SBP/Abran. Diretora-clínica do Centro de Recuperação e Educação Nutricional (CREN) da Unifesp e aluna de doutorado dessa Universidade.

@ - jbporfirio@ig.com.br

Paula Andrea Martins é formada em Nutrição pela Faculdade de Saúde Pública da USP e doutora em Ciências pela Universidade Federal de São Paulo. É professora adjunta do Departamento de Ciências do Movimento Humano do Instituto de Saúde e Sociedade da Unifesp e coordena o grupo de pesquisas em Epidemiologia Nutricional. @-paula.andrea.martins@gmail.com

Renata Cristina Pires é formada em Nutrição pela Faculdade de Saúde Pública da USP, especialista em Fitoterapia pela Faculdade de Ciências da Saúde e aprimoramento em "Recuperação Nutricional: uma abordagem interdisciplinar" pela Unifesp. Nutricionista do Ambulatório do Centro de Recuperação e Educação Nutricional. @ - renatacpires@hotmail.com

Ana Lydia Sawaya é professora associada do Departamento de Fisiologia, Disciplina de Fisiologia da Nutrição da Unifesp. Coordenadora do Grupo de Pesquisa em Nutrição e Pobreza do Instituto de Estudos Avançados da USP. Diretora-científica do Centro de Recuperação e Educação Nutricional. @ - alsawaya@unifesp.br

Recebido em 23.5.2013 e aceito em 17.6.2013. 